\title{
Lubrication Regimes in High-Performance Polymer Spur Gears
}

\author{
K. D. Dearn, ${ }^{1}$ T. J. Hoskins, ${ }^{1}$ L. Andrei, ${ }^{2}$ and D. Walton ${ }^{1}$ \\ ${ }^{1}$ School of Mechanical Engineering, University of Birmingham, Edgbaston, Birmingham B15 2TT, UK \\ ${ }^{2}$ Faculty of Mechanical Engineering, Dunărea de Jos University of Galați, Domneasca 47, 800008 Galați, Romania \\ Correspondence should be addressed to K. D. Dearn; k.d.dearn@bham.ac.uk
}

Received 22 March 2012; Revised 17 October 2012; Accepted 17 October 2012

Academic Editor: Philippe Velex

Copyright (C) 2013 K. D. Dearn et al. This is an open access article distributed under the Creative Commons Attribution License, which permits unrestricted use, distribution, and reproduction in any medium, provided the original work is properly cited.

\begin{abstract}
Little has been published on the behaviour of polymer gears operating under lubricated conditions. An experimental and analytical programme was undertaken to classify the regimes of EHL under which polymer spur gears operate. In doing so theoretical film thicknesses were calculated and then used to classify the regime according to Johnson's Map. The effects of lubrication on the operating efficiencies of high-performance polymer gears were interpreted and from these results coefficients of friction were derived. In addition to this the effect of tooth geometry was investigated and the beneficial influence of high-pressure angle tooth geometry is demonstrated. At loads typically associated with polymer gears the operating regime is shown to be mixed film lubrication. When high-pressure angle gears were tested at high loads the operating regime became full film lubrication and relatively little tooth flank damage occurred.
\end{abstract}

\section{Introduction}

Polymer gears are frequently employed in situations where no external lubrication is permitted, such as in food processing machines and in office equipment, such as printers. Unlubricated (dry) polymer gears are limited in both load and speed due to high frictional forces. This creates high temperatures leading to rapid wear and even melting. Developments in polymer materials (e.g., polymers containing glass fibres and an internal lubricant such as PTFE) and gear tooth geometries have moved polymer gears from motion to power transmitters $[1,2]$. In many of these applications an external lubricant such as grease is permitted. Very few examples of oil or water lubricated polymer gear applications exist. External lubricants can reduce the friction, compared to dry running gears and the lubricant can also act as a coolant. Polymer gears operating under external lubrication permit much higher loads and speeds and offer the possibility of new design solutions to a number of applications traditionally reserved for steel gears.

The reduction of frictional losses in steel gears has been studied by various authors [3, 4]. However, these results are not directly applicable to polymer gear testing. The low modulus of polymer gears makes them resilient when the teeth come into contact. This deformation results in a change in the curvature of the gear tooth, increasing the contact area during tooth contact. Little has been published on externally lubricated polymer gears, the exception being Song et al. [5] who looked at polymer/steel combinations only and compared oil thicknesses and pressures with steel/steel pairs. They reported oil film thicknesses were higher for the polymer/steel combinations than for steel/steel pairs and that the maximum oil film pressure was lower for polymer/steel gears.

A programme of research was carried out in order to explore the potential of polymer gears made from a high performance material (PEEK) and also employing high pressure angle gears not normally used in metal/metal applications. In this paper the authors examined the different forms of elastohydrodynamic lubrication (EHL) and determined which category involute polymer gears fall under. Typical oil film thicknesses are determined and the effect these have on the performance of polymer/polymer and steel/polymer meshes were considered. Typical efficiencies were measured and from these curves, the operating coefficient of friction was determined. Finally, the effect of tooth geometry was examined and the beneficial influence of high tooth pressure angles was demonstrated. 


\section{Elastohydrodynamic Lubrication}

EHL describes the conditions of lubrication usually under nonconformal bearing surfaces, such as those found in machine elements (gearing, cams and rolling-element bearings), where contact occurs over a very small area. Under such conditions, elastic deformation of the bearing surfaces and the effect of the concentrated contact (and associated high pressure) on the viscosity of the lubricant are highly important in determining the effectiveness of the lubricant. EHL is defined in terms of lubricant film thickness and the pressure distribution in the contact area but, ultimately, the success of a lubricant occurs in the prevention of surface asperity contact.

EHL theory describes the regime under which the lubricant operates (defined in terms of the change in lubricant viscosity due to pressure and the extent of elastic deformation in the bearing surfaces). In addition to the above, EHL regimes are also a function of geometry, normal load, sliding and rolling speed. The regime under which a body operates may be determined using a set of dimensionless groups as suggested by Johnson [6]. These he gave as the viscosity parameter, $g_{1}$, the elasticity parameter, $g_{3}$, and $g_{4}$, the system character parameter, given as

$$
\begin{aligned}
& g_{1}=\left(\frac{\alpha^{2} w^{3}}{\eta_{0} \bar{U} R^{2}}\right)^{1 / 2}, \\
& g_{3}=\left(\frac{w^{2}}{\eta_{0} \bar{U} E R}\right)^{1 / 2}, \\
& g_{4}=\left(\frac{\alpha^{4} E^{3} \eta_{0} \bar{U}}{R}\right)^{1 / 4} .
\end{aligned}
$$

Finally, $\bar{h}$ represents the film thickness parameter

$$
\bar{h}=\frac{h_{0} w}{\eta_{0} \bar{U} R} .
$$

On examining the above, it may be observed that the system character parameter $g_{4}$ is a function of both $g_{1}$ and $g_{3}$, and so the prevalent system of lubrication may be readily discerned using only these two parameters.

With a means of defining the operational regime of the lubricant, it is useful to identify each of the regimes in terms of the viscosity and elasticity parameters $\left(g_{1}\right.$ and $\left.g_{3}\right)$ according to Johnson's Map, see Figure 1, where five different regimes can be identified as follows.

(i) Rigid-Isoviscous (RI)

(ii) Rigid-Piezoviscous (RP)

(iii) Elastic-Piezoviscous (EP) (the region in which, typically, steel gears operate)

(iv) Elastic-Isoviscous (EI) (the region in which, typically, rubber seals operate),

(v) Transitional (TR), between EP and EI limits.

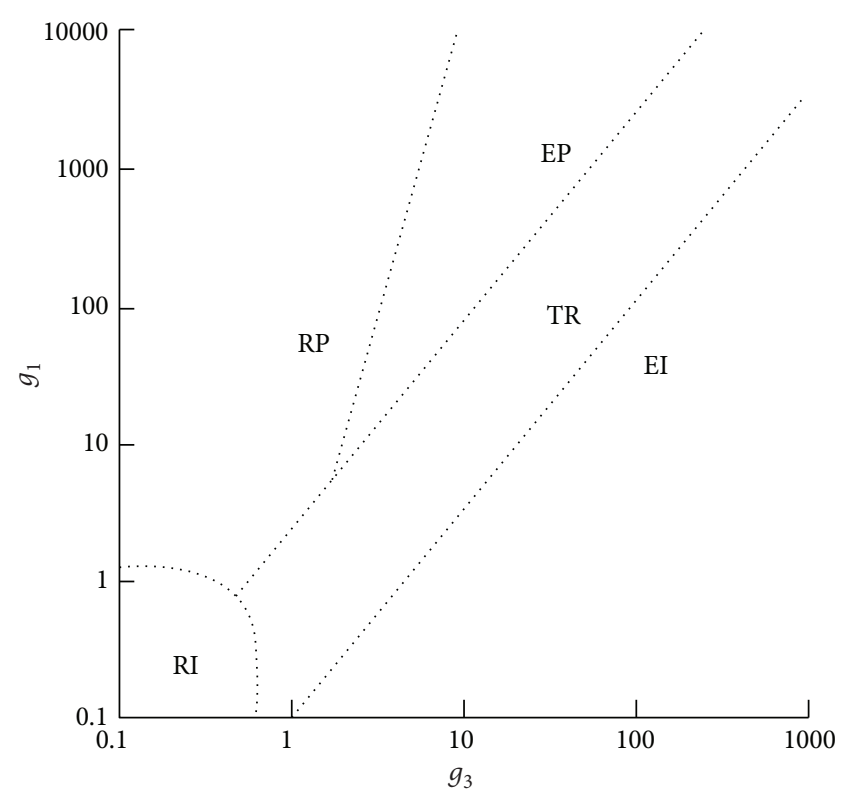

FIGURE 1: The five major regions of elastohydrodynamic lubrication shown on a graph of $g_{1}$ against $g_{3}$ after [7].

It is the TR region $\left(0.1<g_{4}<2.2\right)$ that Johnson suggests that applies to polymers lubricated with a mineral oil [3]. Myers et al. [7] provides a solution for calculating the dimensionless minimum film thickness of the lubricant that fall within this region, as:

$$
\begin{aligned}
\bar{h} & =0.383 g_{1} g_{3}{ }^{-0.379}+4.465 g_{3}{ }^{0.667} \quad 1<g_{3}<15, \\
& =0.853 g_{1} g_{3}{ }^{-0.664}+3.41 g_{3}{ }^{0.77} \quad 1<g_{3}<100 .
\end{aligned}
$$

When $\bar{h}$ has been established, the actual film thickness can be calculated thus [5]

$$
h=\frac{\bar{h} \eta_{0} \bar{U} R}{w} .
$$

Finally, (7) is used to determine the likelihood and severity of asperity contact (specific film thickness), where $R_{a t}$ is defined as the root-mean-square of the combined surface roughness of the bearing surfaces and is given in (8):

$$
\lambda=\frac{h}{R_{a t}},
$$

where

$$
R_{a t}=\sqrt{R_{a 1}^{2}+R_{a 2}^{2}} .
$$

As stated above, in ideal conditions EHL will ensure that no contact is made between bearing surfaces, which are separated by a lubricant film (the so-called full film conditions). This is said to occur at specific film thicknesses in excess of 3 [8]. As the specific film thickness decreases, asperity contact (and thus friction and wear) will increase until at a specific film thickness of approximately 1, the bearing surfaces will be 
in constant contact but the load will still be supported by an under-developed lubricant film (partial or mixed EHL). The dominant mode of lubrication changes to that of boundary lubrication at specific film thickness $(h)$ values less than 1 .

It is, however, difficult to define a minimum specific film thickness for gearing applications. Cropper [1] suggests that opinions differ significantly as to an acceptable value. These all relate, however, to steel gears. During a limited research programme Walton et al. [9] observed no wear in Nylon 6-6 composite gears for specific film thicknesses of 0.43 . This can be attributed to the elastic deformation of polymer surface asperities (particularly when in dissimilar material gear meshes) smoothing out the gear tooth flank surface [10]. This suggests that surface roughness for a polymer gear is of less importance in EHL than for a similar steel gear.

The solution for minimum film thickness in the transition regime suggested by Myers et al. [7] assumes Newtonian fluid behaviour, isothermal and steady state conditions with pure rolling and perfectly smooth surfaces. The first two assumptions are of little significance due to the increased compliance (and hence lower pressure in the contact area) for polymer gears.

The assumption of steady state conditions within the contact zone is more tenuous. All film thickness calculations are based on a quasi-steady state criterion developed by Gu [11], where instantaneous points on the line of contact are in turn represented by an instantaneous value of curvature, speed, and load that is independent of the previous step. Caution should be applied to any of these results, as the complex nature of tooth meshing action (such as the dependence on previous contact history and rates of change of these values) mean that this will be an imperfect model [12]. The assumption of pure rolling holds at the pitch point (Figure 2); however, Dowson also states that reasonable accuracy may be expected away from the pitch point. A small modification to the calculation of the entraining velocity is discussed below to account for both rolling and sliding during the gear meshing cycle.

Given the above, it is considered that the dimensionless film thickness values calculated from Myers et al. solutions may be employed without further modification. If the EHL theories are applied at the tooth mesh pitch point, the majority of the assumptions are satisfied.

When applying EHL theory to polymer involute spur gears, the complexities of gear meshing kinematics may be simplified. At any instantaneous point during the meshing cycle, the geometry of the interacting surfaces may be approximated as two cylinders, having the radii of curvature of the two involutes at the point of contact. Thus, the radius of the equivalent cylinder $R^{\prime}$ is a function of these radii (which themselves change along the path of contact) and so is a function of the meshing position. A similar approximation may be made when determining the elasticity of the bearing surfaces. As both gear flanks are elastic, an equivalent modulus of elasticity, $E^{\prime}$ can be determined (for plain strain conditions and assuming infinitely wide contacts). This assumes linear isotropic material behaviour and does not account for the viscoelastic nature of polymers.
A small modification to the Myers et al. solution can be made to account for the combination of rolling and sliding during the meshing cycle. The entraining velocity in gearing applications is given thus:

$$
\bar{U}=\omega_{1} r_{1} \sin \psi=\omega_{2} r_{2} \sin \psi
$$

The entraining velocity relationship may be further simplified, when a gear ratio of 1 is employed as is the case with the gears used in this experimental programme. The entraining velocity then becomes:

$$
\bar{U}=\omega r \sin \psi .
$$

Finally, the loads used in EHL calculations must represent the load per unit cylinder length (which in this case will be the facewidth of the gears). However, the load will vary according to the load distribution that is governed by the selected contact ratio. Due to the large deflections in polymer gears, real load sharing (and hence the real contact ratio) will be quite different to theoretical predictions [13]. Walton et al. [14] suggested that the most severe conditions are likely to occur at the pitch point (which will be the same value for both theoretical and real conditions and so are representative of the most severe conditions).

\section{Efficiency of Polymer Spur Gears}

Walton et al. [10] showed that the efficiency of polymer gears is a function of the gear geometry and the mesh coefficient of friction only. They showed that the efficiency can be given as

$$
\eta=1-\left(\frac{1+1 / i}{\gamma_{a 1}+\gamma_{r 1}}\right) \frac{\mu}{2}\left({\gamma_{a 1}}^{2}+{\gamma_{r 1}}^{2}\right) .
$$

In the case of the benchmark gears tested both pinion and driver gears have the same number of teeth and so (11) reduces to

$$
\gamma_{a}=\gamma_{r}=\gamma
$$

Hence from (11) the efficiency becomes

$$
\eta=1-\mu \gamma
$$

giving simply

$$
\mu=\frac{1-\eta}{\gamma}
$$

By measuring the efficiency of dry-running running gears they were able to back-calculate the coefficient of friction. An interesting aspect of this work was that as the load was increased the efficiency also increased. In the case of $\mathrm{POM} / \mathrm{POM}$ pairs this was particularly evident. In the present work for externally lubricated gears the efficiency is also shown to be a function of load for some gear materials. 

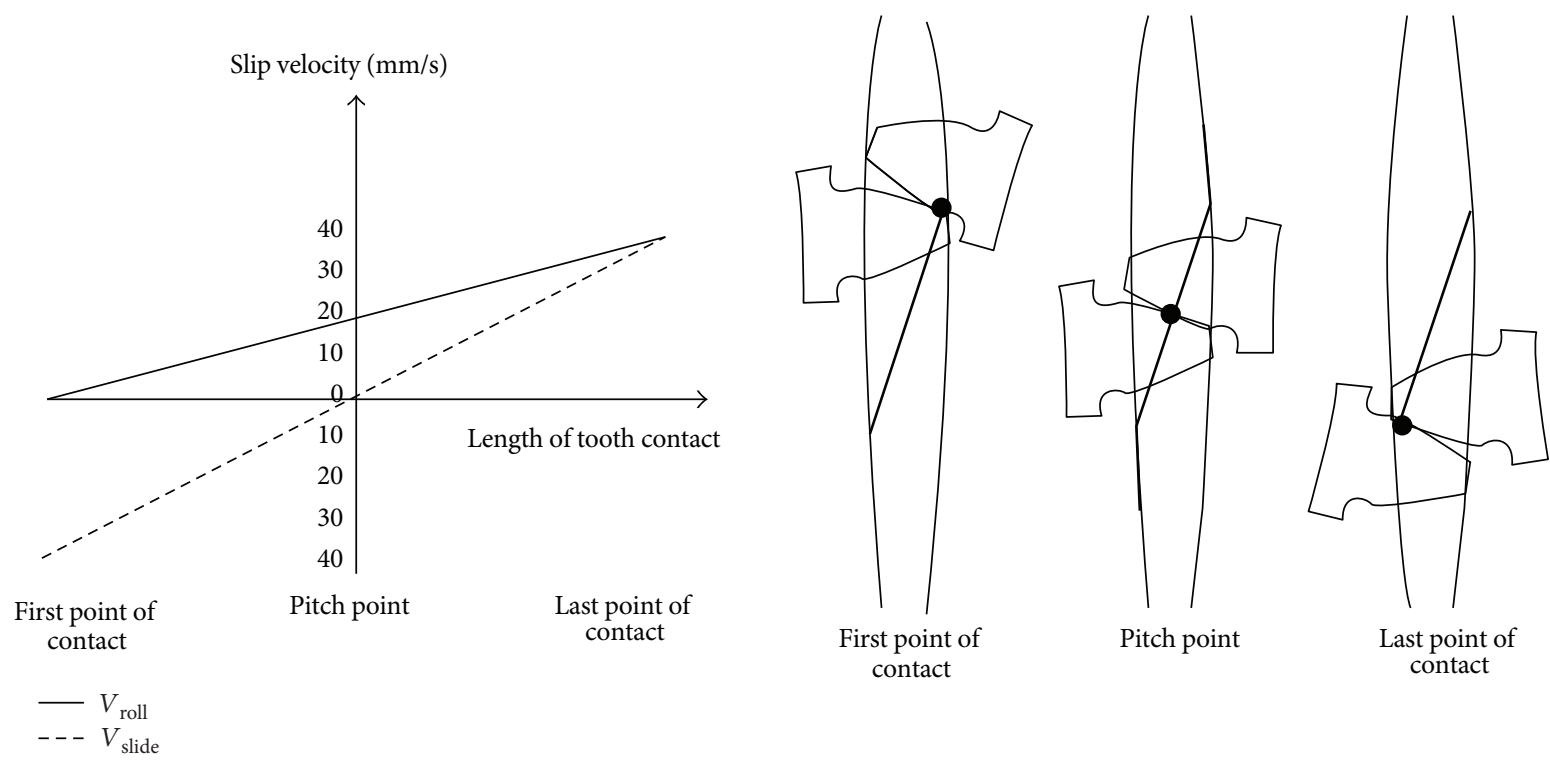

FIGURE 2: The line of contact and the rolling/sliding speeds along the contact path.

\section{Experimental Programme}

The efficiency of the polymer gears tested was measured on a test rig, details of which are given by Walton et al. [10]. This is an open loop gear test rig. The rig was designed to test polymer gears up to a maximum torque of $10 \mathrm{Nm}$ and a maximum running speed of $3000 \mathrm{revs} / \mathrm{min}$. A feature of this rig is that the input and output torques can be measured and also that the gears can be run under no load, permitting the non-gear losses (such as bearing and seal friction) to be measured and subtracted from the input and output torques. This permitted accurate efficiency measurements to be made. Another important feature of the rig is that running under no load the oil churning losses (which are a function of the gearbox case design) can also be subtracted resulting in only tooth mesh losses being measured. Input and output torques were measured to an accuracy of $0.01 \mathrm{Nm}$, with the relative rotation of the gears measured to 0.005 degrees. For accuracy the rig was calibrated under steady state conditions.

Tests were carried out on "standard" gear tooth forms $\left(20^{\circ}\right.$ pressure angles, 30 teeth, module $2 \mathrm{~mm}$, and $17.4 \mathrm{~mm}$ facewidth). Other tests were carried on $30^{\circ}$ pressure angle gears having the same tooth number, module, and facewidth. Tests were carried out in automotive engine oil with a SAE viscosity rating of $15 \mathrm{~W} 50$ (137.7 cSt at ambient temperature).

\section{Results and Discussion}

Figure 3 shows the calculated variation of the film thickness for a polymer gear pair where both driver and driven gears are of the same materials (in this case PEEK- polyetheretherketone) and for pressure angles of $20^{\circ}$ and $30^{\circ}$. The sudden change in the curve denotes the effect of load sharing which takes place during each full mesh. The expected result of a higher film thickness for the high pressure angle gears is quite prominent, due to the higher entrainment velocities (see
Table 1). The entraining velocity, defined in (10), accounts for the kinematic complexity of the meshing gear tooth flanks and considers both rolling and sliding motion. The difference between the sliding and rolling velocities, given in Table 1, suggest that there is a prevalent rolling motion in the $30^{\circ}$ gears. The greater difference between the two values (higher values of entraining velocity and lower values of sliding velocity) is likely to be manifest as lower running temperatures and reduced tooth flank wear. The shorter path of contact is also to be seen for the high pressure angle gears. Of significance is the fact that as the surface roughness for the PEEK gears is around 40 microns thus for both gear pairs the specific film thickness is less than 1. Figure 4 shows variations in film thickness according to meshing materials. The polymer/steel gear pairs show a lower film thickness than the polymer/polymer g ears. This is in accordance with the findings of Song et al. [5]. The differences in film thicknesses may be attributed to the elastic deformations in the mesh contact zones. In the polymer/polymer mesh the deformation will be shared by both driver and driven gears whereas for the polymer/steel mesh deformation will be almost entirely on the polymer gear. Figures 3 and 4 are given at a load of 10 $\mathrm{Nm}$ and a speed of $1500 \mathrm{revs} / \mathrm{min}$.

Figure 5 shows the effect of running speed on film thicknesses for polymer/polymer gears at a torque of $10 \mathrm{Nm}$. As the speed was increased so the film thicknesses also increased. The step between single and multiple tooth contact increases with speed, an entrainment velocity effect. Figure 6 shows the effect of load on film thicknesses, where, as expected, the film thickness decreases with load. Note that for all of the film thickness figures, the curves are shown assuming ideal load sharing. In practice, as shown by Karimpour et al. [13], the line of contact increases significantly for low modulus polymer gears, effectively increasing the contact ratio. This would have the effect of smoothing the transition between single and multiple tooth contact. 


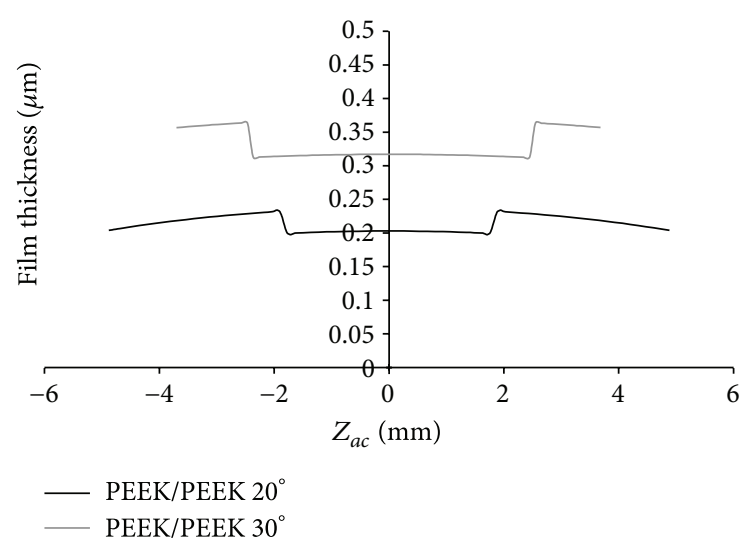

Figure 3: Minimum film thickness across the line of contact for PEEK/PEEK $20^{\circ}$ and $30^{\circ}$ pressure angle gears.

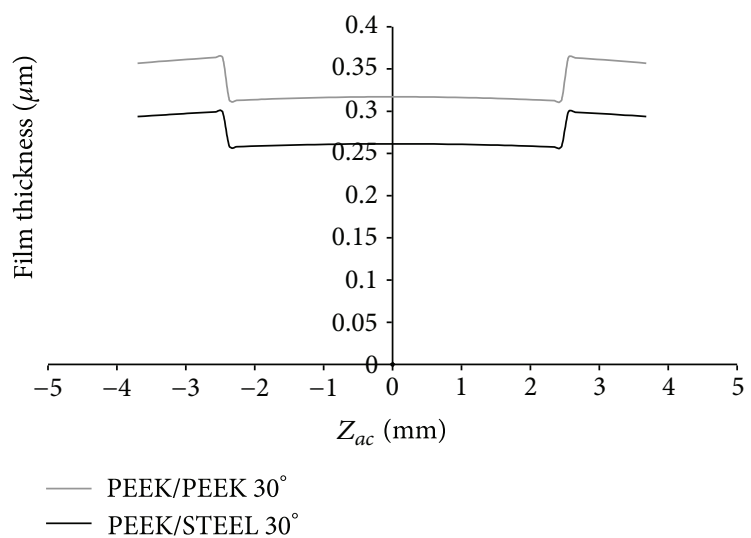

FIGURE 4: Minimum film thicknesses across the line of contact for PEEK/PEEK and PEEK/STEEL $30^{\circ}$ pressure angle gears.

TABLE 1: Entraining and sliding velocities for $20^{\circ}$ and $30^{\circ}$ pressure angle gears.

\begin{tabular}{lcccc}
\hline $\begin{array}{l}\text { Rotational Speed } \\
\text { revs/min }\end{array}$ & $20^{\circ}$ & $30^{\circ}$ & $20^{\circ}$ & $30^{\circ}$ \\
\hline 50 & 0.05 & 0.08 & 0.05 & 0.04 \\
250 & 0.27 & 0.39 & 0.26 & 0.19 \\
500 & 0.54 & 0.79 & 0.51 & 0.39 \\
1000 & 1.07 & 1.57 & 1.03 & 0.77 \\
1500 & 1.61 & 2.36 & 1.54 & 1.16 \\
2000 & 2.15 & 3.14 & 2.05 & 1.54 \\
3000 & 3.22 & 4.71 & 3.08 & 2.31 \\
\hline \multicolumn{5}{c}{ Entraining Velocity } \\
\multicolumn{2}{c}{ (m/s) } & \multicolumn{2}{c}{ Sliding Velocity } \\
\hline
\end{tabular}

Figure 7(a) shows measured efficiencies for PEEK running against PEEK for $20^{\circ}$ pressure angle gears. This figure shows that, as in dry running contacts, there is a load dependency, with the efficiency increasing with load [10]. As for dry running contacts the elastic deformation of the gear tooth flanks results in a "smoothing" effect and a reduction of surface friction. There is also a weaker speed dependency,

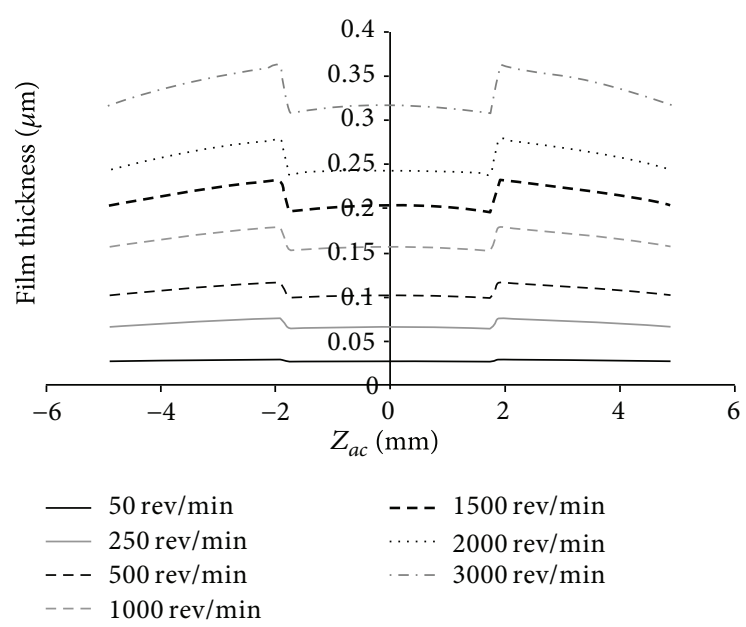

FIGURE 5: Variation in minimum film thicknesses according to rotational speed across the line of contact.

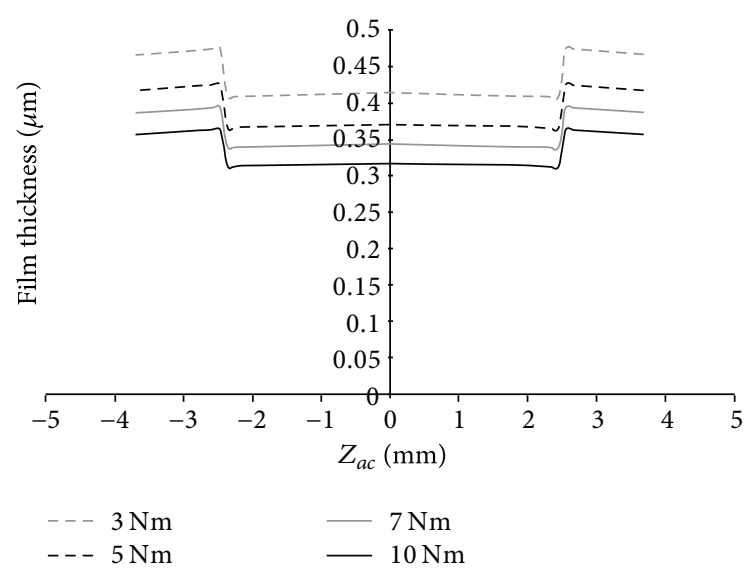

FIGURE 6: Variation in minimum film thicknesses according to applied load across the line of contact.

where the efficiencies are higher at low and starting speeds. This is in keeping with the frictional characteristics of polymers. Note that in all the efficiency figures shown in this paper, oil churning and spindle/bearing losses have been subtracted. Figure $7(\mathrm{~b})$ shows the derived coefficients of friction calculated from the measured efficiencies and by using (14). While the coefficients of friction show the dependency of load, the curves are relatively flat with respect to speed.

Figure 8 (a) shows the efficiency of PEEK running against itself for $30^{\circ}$ pressure angle gears. There are only minor improvements compared to the efficiencies of $20^{\circ}$ pressure gears. The derived coefficient of friction (given in Figure 8(b)) shows little variation with speed except for the low (3 Nm) load. Figure 9(a) shows the measured efficiencies for PEEK running against steel (where PEEK is the driven gear, the teeth being of $20^{\circ}$ pressure angle). Compared to the PEEK/PEEK results the efficiencies are lower, possibly explained by the large tooth deformations occurring on 


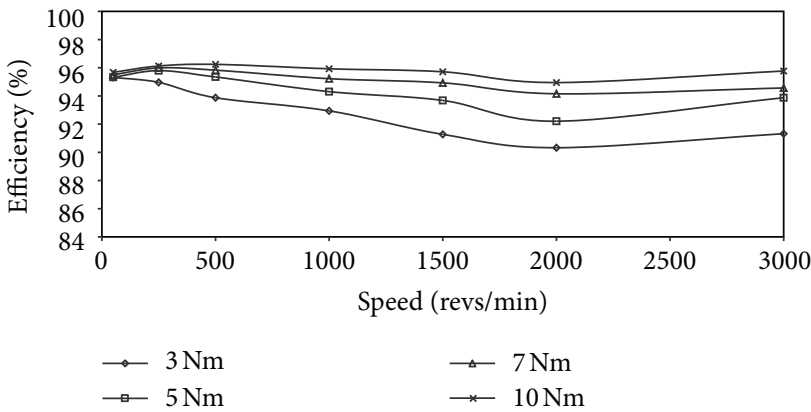

(a)

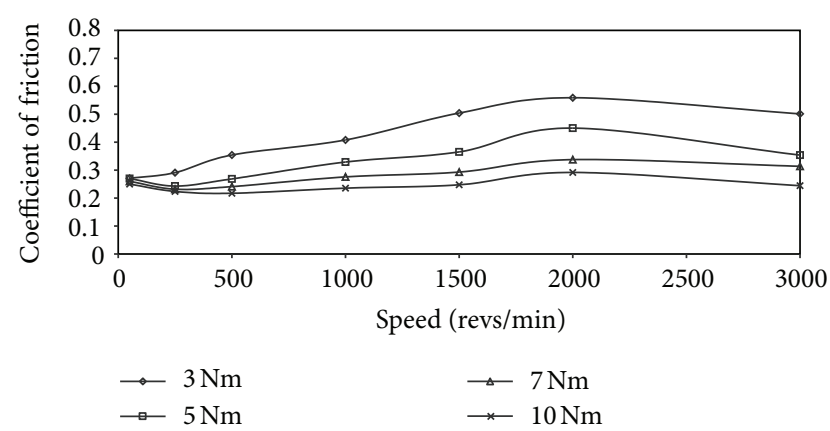

(b)

FIgURE 7: Showing (a) the efficiency and (b) the derived coefficients of friction for $20^{\circ}$ pressure angle PEEK/PEEK gear combinations.

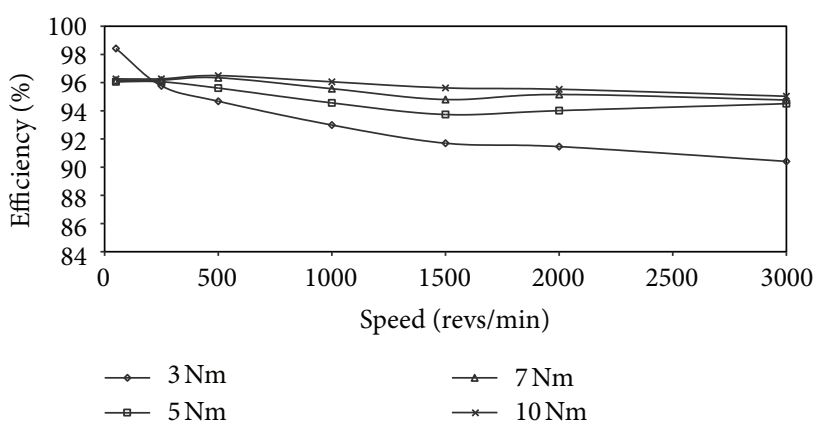

(a)

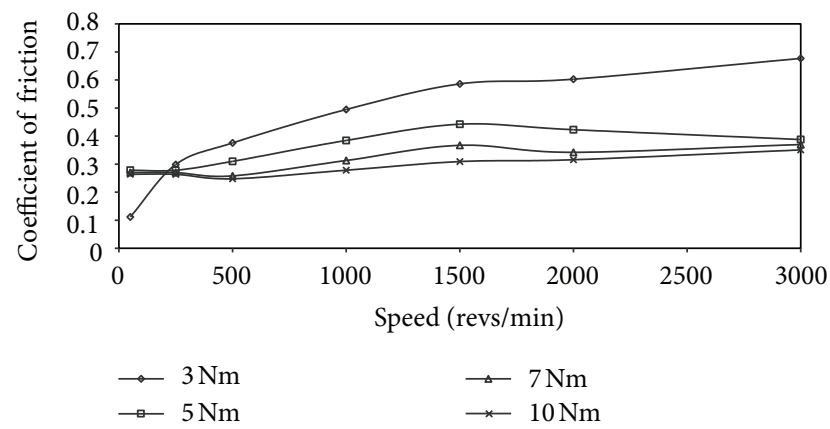

(b)

FIgURE 8: Showing (a) the efficiency and (b) the derived coefficients of friction for $30^{\circ}$ pressure angle PEEK/PEEK gear combinations.

the polymer gear. Figure 9(b) shows the derived coefficients of friction for the PEEK/steel combination. Finally, Figures 10(a) and 10(b) show the efficiency and derived coefficients of friction for $30^{\circ}$ pressure angle PEEK/steel gears. Both graphs show similar trends to the $20^{\circ}$ pressure angle PEEK/steel combinations.

In all of the efficiency tests, the efficiency (and coefficient of friction) was shown to be weakly dependant on speed. However, the correlation with load was must stronger, with large increases with increases in applied loads. This is an observation that was made by Walton et al. in their dry-running experiments. They attributed the increase in efficiency with load to a high-quality surface finish [10]. The surface roughness of the gears described in this paper, was measured at $0.4 \mu \mathrm{m}$, and this is the equivalent to a polished steel gear surface. The topography is likely to have led to elastic flattening of the asperities in the contact area and a subsequent reduction in sliding resistance. Asperity smoothing and the resulting reduction in surface roughness is also likely to have assisted in the development of an oil film between the tooth flanks and this is reflected in Figure 6.

\section{Failure Modes}

Dry running polymer gears including polymer/steel interfaces fail mainly due to gross wear or fatigue. Pitting does not occur. In the lubricated tests described in this paper gross pitting was found to occur at high loads and speeds. The pitting extended over the whole of the tooth flank and was not local to the pitch line as in lubricated metal/metal contacts. The size of the pits does, for polymer gears, decrease with distance from the pitch line.

The Océ test rig is limited to a maximum load of $10 \mathrm{Nm}$. In an attempt to discover the maximum potential of polymer gears the test rigs (power recirculating type, Kono [15]) in the Power Transmission Laboratory in Birmingham were used as these rigs are capable of running at high speeds and loads (4500 revs/min and $40 \mathrm{Nm}$ ). The power recirculating rigs do not permit efficiencies to be measured. Thus only the surface deterioration was measured. PEEK/PEEK gear combinations with $20^{\circ}$ and $30^{\circ}$ pressure angles (and the same geometry as the gears described in this paper) were tested at loads up to $27 \mathrm{Nm}$ with Hertzian contact pressures at the pitch point of the gears ranging from (191.2 $\mathrm{MPa}$ to $222.5 \mathrm{MPa}$ ). Under these conditions the gears were, theoretically operating at full film lubrication $(\lambda$ greater than 1$)$. Examination of the gears running for up to $2 \times 107$ cycles exhibited some wear (the $30^{\circ}$ pressure angle gears had virtually no wear while the $20^{\circ}$ pressure angle gears exhibited extreme wear and gross pitting). Figure 11 (a) shows a $20^{\circ}$ pressure angle gear run at $17 \mathrm{Nm}$. This shows the extreme pitting close to the pitch line and more moderate pitting along the whole flank. Figure 11(b) shows the profile change for the same gear over running time measured by a coordinate measuring machine. 


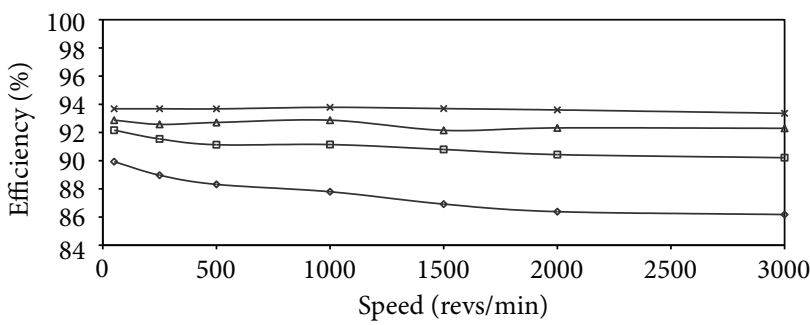

$$
\begin{array}{ll}
\rightarrow 3 \mathrm{Nm} & \rightarrow 7 \mathrm{Nm} \\
\rightarrow 5 \mathrm{Nm} & \rightarrow 10 \mathrm{Nm}
\end{array}
$$

(a)

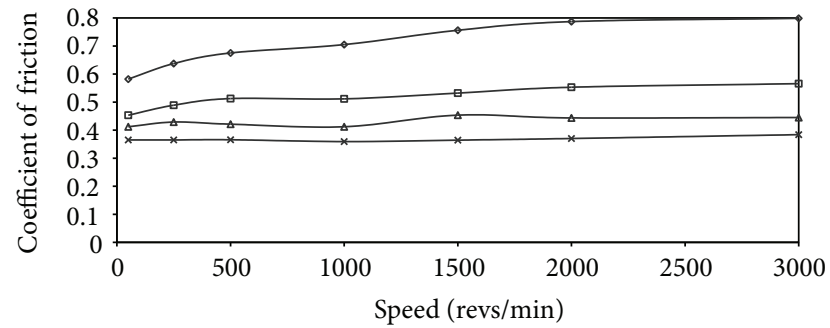

$$
\begin{array}{ll}
\rightarrow 3 \mathrm{Nm} & \rightarrow 7 \mathrm{Nm} \\
\rightarrow 5 \mathrm{Nm} & \rightarrow 10 \mathrm{Nm}
\end{array}
$$

(b)

FIGURE 9: Showing (a) the efficiency and (b) the derived coefficients of friction for $20^{\circ}$ pressure angle PEEK/steel gear combinations.

\begin{tabular}{|c|c|}
\hline$\diamond 3 \mathrm{Nm}$ & $* 3 \mathrm{Nm}$ \\
\hline$\square 5 \mathrm{Nm}$ & $\rightarrow 5 \mathrm{Nm}$ \\
\hline$\triangle 7 \mathrm{Nm}$ & $-7 \mathrm{Nm}$ \\
\hline$\times 10 \mathrm{Nm}$ & $=10 \mathrm{Nm}$ \\
\hline
\end{tabular}

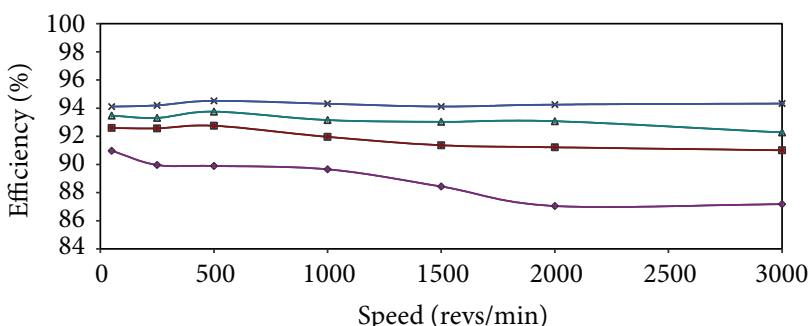

(a)

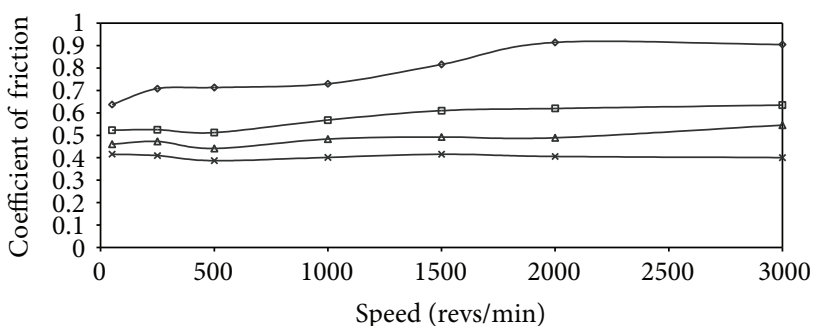

$$
\begin{array}{ll}
\rightarrow 3 \mathrm{Nm} & \rightarrow 7 \mathrm{Nm} \\
\square 5 \mathrm{Nm} & \rightarrow 10 \mathrm{Nm}
\end{array}
$$

(b)

FIGURE 10: Showing (a) the efficiency and (b) the derived coefficients of friction for $30^{\circ}$ pressure angle PEEK/steel gear combinations.

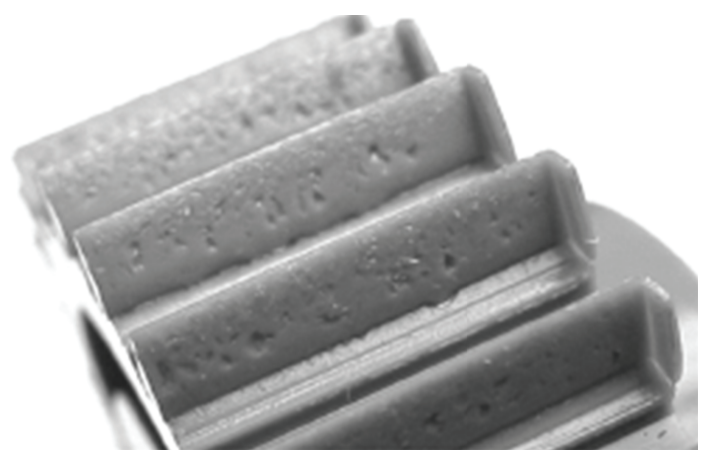

(a)

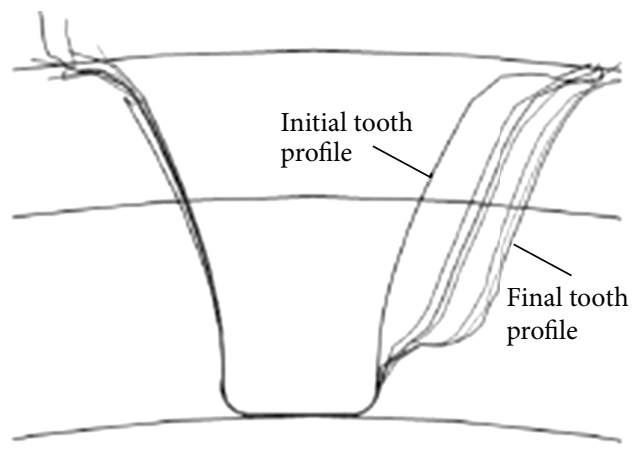

(b)

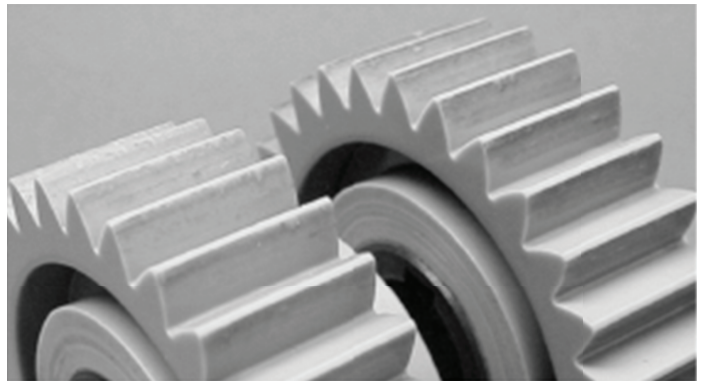

(c)

Figure 11: showing (a) a $20^{\circ}$ pressure angle gear ran at $17 \mathrm{Nm}$, (b) the profile change over running time for the same gear, and (c) a pair of $30^{\circ}$ pressure angle gears run at two different loads ( $17 \mathrm{Nm}$ on the left and $22 \mathrm{Nm}$ on the right). 
Figure $11(\mathrm{c})$ shows a pair of $30^{\circ}$ pressure angle gears run at two different loads ( $17 \mathrm{Nm}$ on the left and $22 \mathrm{Nm}$ on the right). These show little wear and no pitting.

\section{Conclusions}

Employing the nondimensional viscosity and elasticity parameters $\left(g_{1}\right.$ and $\left.g_{3}\right)$ the film thicknesses for polymer/polymer and polymer/steel gears running in oil were determined using the Myers et al. solution. As a result the specific film thickness was established. This enabled the operating regime to be classified. This was found to be in the transitional region of Johnson's elastohydrodynamic lubrication map. The gears were therefore operating under mixed film conditions. As such they exhibit some of the characteristics of dry running polymer gears. Even under these conditions the efficiencies are not as high as might be expected compared to dry running results. However, the Hertzian contact patch, particularly under dissimilar material meshes, is large (at $10 \mathrm{Nm}$ typically $0.5 \mathrm{~mm}$ ) and in the contact zone considerable flattening occurs leading to low oil film pressures.

The efficiencies for all the results shown in this paper bore similarities in that higher operating loads (i.e., torques) resulted in higher efficiencies. This is in common with dry running polymer gears. Derived coefficients of friction showed that high values can result, for example, for PEEK/steel combination the coefficients of friction can be greater than 0.8 . These are very much higher than coefficients of friction for oil lubricated steel/steel gears and are likely to be a contributive factor in causing severe pitting damage.

Gears run at higher loads than those permitted by the open loop test rig where the specific film thickness exceeded unity demonstrated (in the case of the $30^{\circ}$ pressure angle gears) no wear or pitting showing full film lubrication. Gears designed with high pressure angles are not normally used in conventional steel gear applications. This is because they are regarded as being noisy due to the fact that these gears have a low contact ratio. Another problem usually associated with these gears is the limit to center distance extension, In the case of high pressure angle polymer gears, due to the compliance of the material, no noise problems were experienced. This programme has demonstrated that oil lubricated gears employing a novel $30^{\circ}$ pressure angle have the potential for high performance applications and closes the gap between metallic and polymer gears. As an example, a project was carried out in which an automobile epicyclic gearbox was designed employing PEEK gears [16].

\section{Notations}

$$
\begin{array}{ll}
E: & \text { Elastic modulus }(\mathrm{MPa}) \\
1 / E^{\prime}= & \text { equivalent modulus }(\mathrm{MPa}) \\
(1 / 2)\left(\left(1-\sigma_{1}\right) / E_{1}+\right. & \\
\left.\left(1-\sigma_{2}\right) / E_{2}\right): & \\
g_{1}: & \text { Viscosity parameter } \\
g_{3}: & \text { Elastic parameter } \\
g_{4}: & \text { System character parameter }
\end{array}
$$

$\begin{array}{ll}h: & \text { Actual film thickness }(\mu \mathrm{m}) \\ h_{0}: & \text { Central lubricant film thickness } \\ & (\mu \mathrm{m}) \\ \bar{h}: & \text { Film thickness parameter } \\ i: & \text { Gear ratio } \\ R: & \text { Radius of curvature }(\mathrm{m}) \\ R^{\prime}=R_{1} R_{2} /\left(R_{1}+R_{2}\right): & \text { equivalent radius }(\mathrm{m}) \\ R_{a}: & \text { Surface roughness-RMS }(\mu \mathrm{m}) \\ R_{a t}: & \text { Equivalent surface roughness (for } \\ r: & \text { both contacting surfaces) }(\mu \mathrm{m}) \\ \bar{U}: & \text { Pitch circle radius }(\mathrm{m}) \\ w: & \text { Entraining velocity }\left(\mathrm{ms}^{-1}\right) \\ Z_{a c}: & \text { Load/unit facewidth }\left(\mathrm{Nm}^{-1}\right) \\ \alpha: & \text { Line of contact (mm) } \\ \eta_{0}: & \text { Pressure viscosity index }\left(\mathrm{Pa}{ }^{-1}\right) \\ \sigma: & \text { Viscosity of lubricant at ambient } \\ \lambda: & \text { temperature and pressure }(\mathrm{Pa} \cdot \mathrm{s}) \\ \omega: & \text { Poisson's ratio } \\ \psi: & \text { Specific film thickness (mm) } \\ \eta: & \left.\text { Rotational velocity (rev }{ }^{-1}\right) \\ \gamma: & \text { Pressure angle (degrees) } \\ \mu: & \text { Plastic spur gear efficiency }(\%) \\ & \text { Arc of gear rotation }(\text { degrees) } \\ & \text { Coefficient of friction. }\end{array}$

\section{Subscripts}

1: Driver gear

2: Driven gear

a: Approach phase of gear mesh

$r$ : Recess phase of gear mesh.

\section{Acknowledgments}

The authors would like to thank Dr. A. B. Cropper of Smiths Aerospace, UK and Mr. P. Klein-Meuleman of Océ, The Netherlands, for their assistance in obtaining the efficiency data.

\section{References}

[1] A. B. Cropper, Failure mode analysis of plastic gears [Ph.D. thesis], University of Birmingham, UK, 2003.

[2] T. J. Hoskins, K. D. Dearn, S. N. Kukureka, and D. Walton, "Acoustic noise from polymer gears-a tribological investigation," Materials and Design, vol. 32, no. 6, pp. 3509-3515, 2011.

[3] B. Höhn, K. Michaelis, and M. Hinterstoißer, "Optimization of gearbox efficiency," Tech. Rep., pp. 462-480, Goriva i Maziva, 2009.

[4] R. Handschuh and A. Zakrajsek, "High pressure angle gears: preliminary testing results," Tech. Rep. NASA/TM-2010216251, 2010.

[5] K. Song, Y. Wang, B. Huang, and M. Wang, "Study on EHL of plastic pinion engaging with steel gear," Lubrication Engineering, no. 1, pp. 50-54, 2005.

[6] K. L. Johnson, "Regimes of elastohydrodynamic lubrication," Journal of Mechanical Engineering Science, vol. 12, no. 1, pp. 9-16, 1970. 
[7] T. G. Myers, R. W. Hall, P. H. Savage, and P. H. Gaskell, "The transition region of elastohydrodynamic lubrication," Proceedings of the Royal Society A, vol. 432, no. 1886, pp. 467-479, 1991.

[8] I. M. Hutchings, Tribology: Friction and Wear of Engineering Materials, Arnold, London, UK, 1992.

[9] D. Walton, J. White, and W. K. Vonach, "EHL in polymer composite gears," Internal Report 97-006, Power Transmission Laboratory, 1997.

[10] D. Walton, A. B. Cropper, D. J. Weale, and P. K. Meuleman, "The efficiency and friction of plastic cylindrical gears. Part 1: influence of materials," Proceedings of the Institution of Mechanical Engineers J, vol. 216, no. 2, pp. 75-92, 2002.

[11] A. Gu, "Elastohydrodynamic lubrication of involute gears Soviet atomic energy," Tech. Rep. 72 PTG-34 8-12, 1972.

[12] D. Dowson and G. R. Higginson, Elastohydrodynamic Lubrication, Pergamon Press, Oxford, UK, 1966.

[13] M. Karimpour, K. D. Dearn, and D. Walton, "A kinematic analysis of meshing polymer gear teeth," Proceedings of the Institution of Mechanical Engineers L, vol. 224, no. 3, Article ID 146442, pp. 101-115, 2010.

[14] D. Walton, A. A. Tessema, C. J. Hooke, and J. M. Shippen, "Load sharing in metallic and non-metallic gears," Proceedings of the Institution of Mechanical Engineers C, vol. 208, no. 2, pp. 81-87, 1994.

[15] S. Kono, Increase in power density of plastic gears for automotive applications [Ph.D. thesis], University of Birmingham, West Midlands, UK, 2003.

[16] T. F. Osman, Non-metallic automotive gearbox [M.S. thesis], University of Birmingham, West Midlands, UK, 2004. 

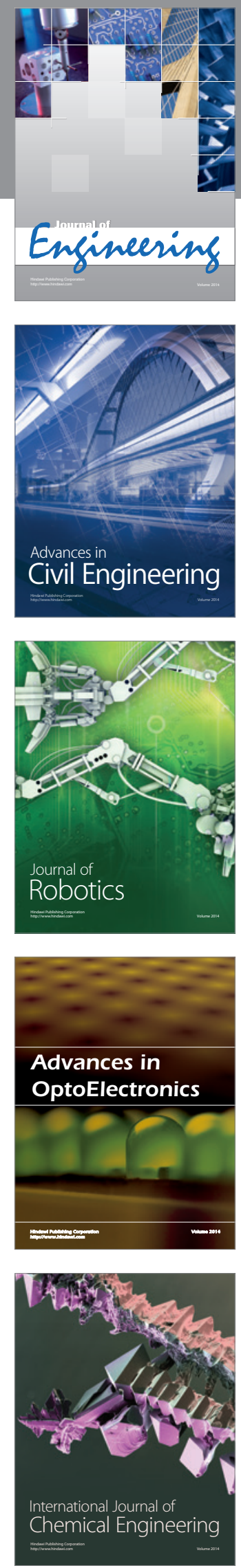

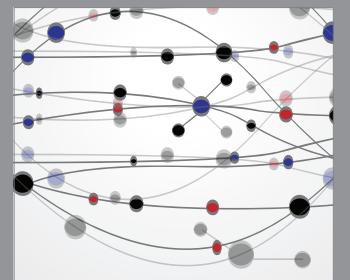

The Scientific World Journal
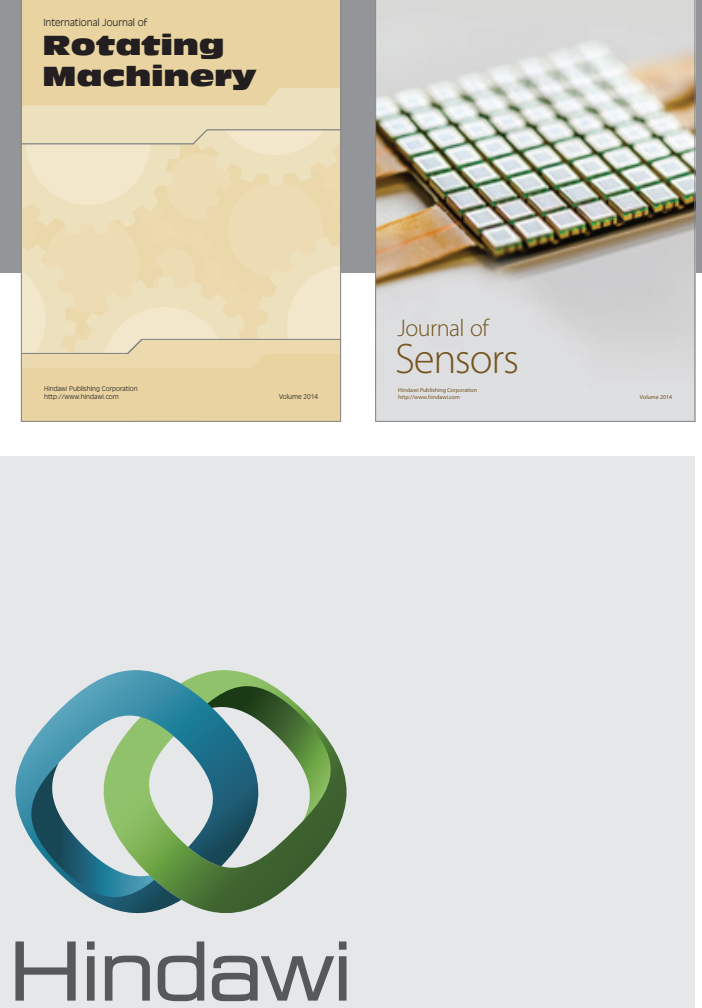

Submit your manuscripts at http://www.hindawi.com
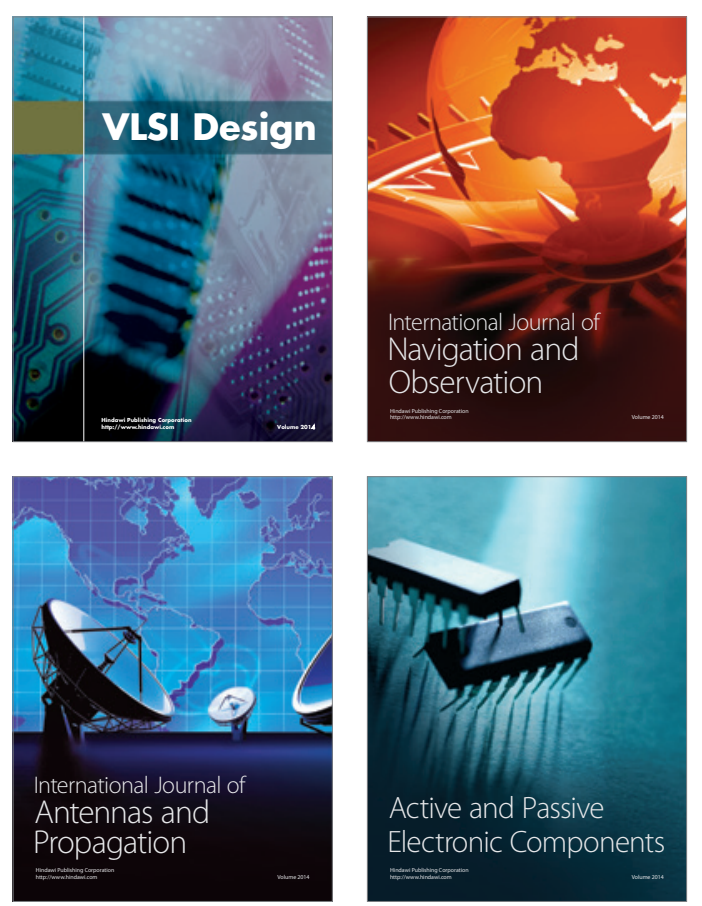
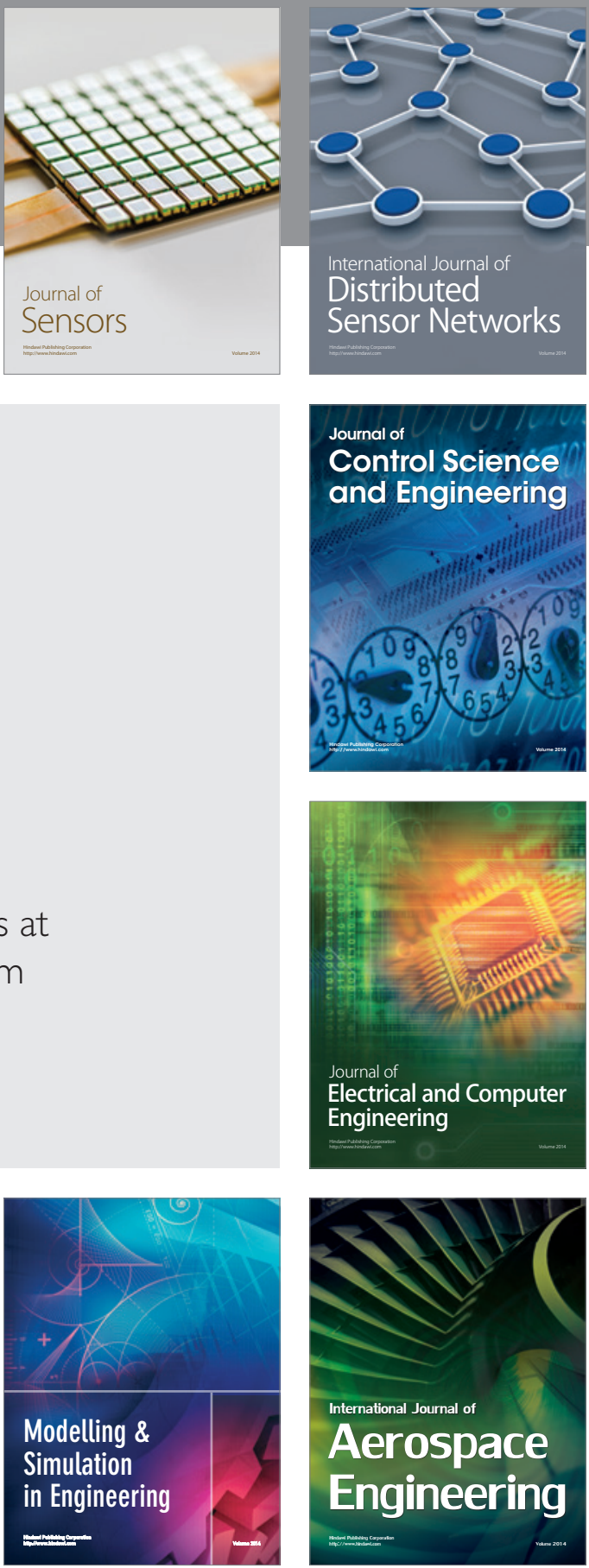

Journal of

Control Science

and Engineering
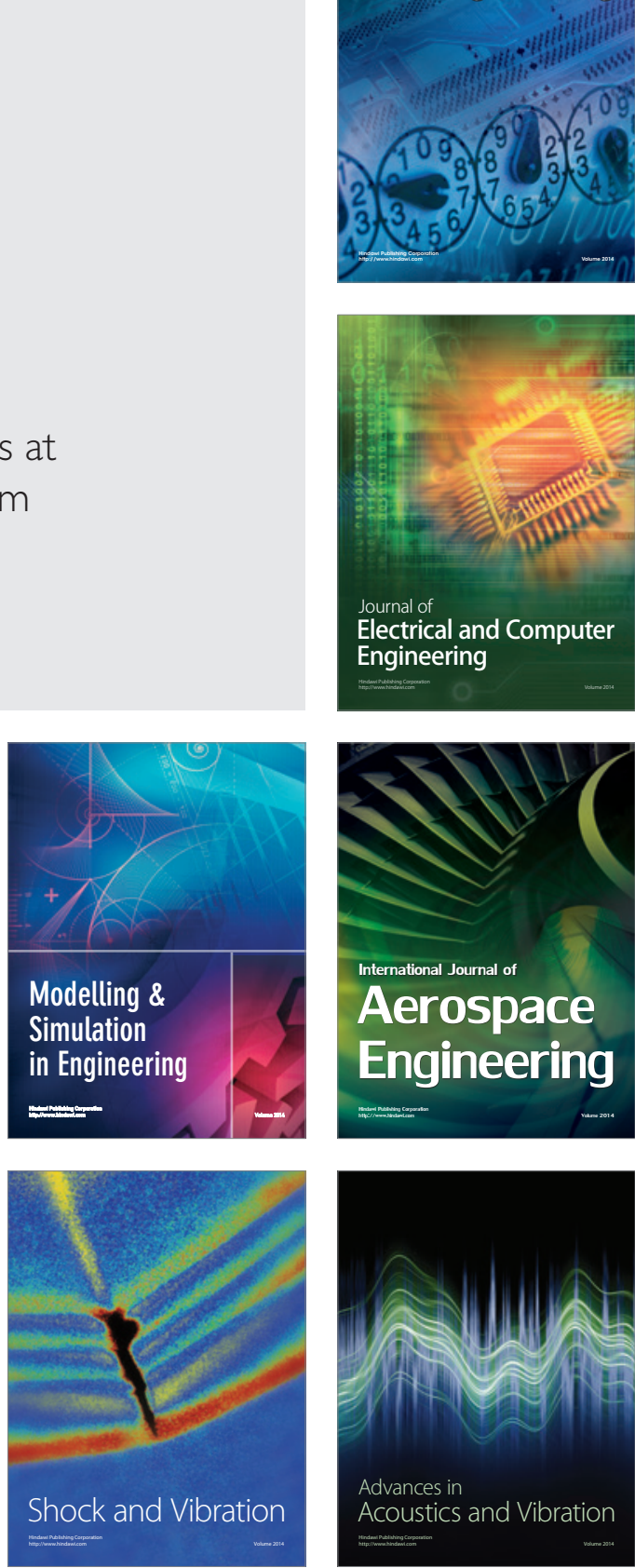